\title{
A COMPARATIVE APPROACH TO THE VERTEBRATE MUSCULOSKELETAL SYSTEM IN PRIMARY SCHOOL
}

\author{
Sara Tonon ${ }^{1}$, Paola Bisaccia ${ }^{2}$, Marco Bonato ${ }^{3}$, Paola Irato ${ }^{4}$, Francesca Corrà ${ }^{5}$ \\ Gianfranco Santovito ${ }^{6 *}$ \\ ${ }^{1} \mathrm{Dr}$, University of Padova, ITALY, sara.tonon_s@libero.it \\ ${ }^{2}$ Dr, University of Padova, ITALY, bisaccia.paola@gmail.com \\ ${ }^{3} \mathrm{Dr}$, University of Padova, ITALY, marco.bonato@unipd.it \\ ${ }^{4}$ Dr, University of Padova, ITALY, paola.irato@unipd.it \\ ${ }^{5} \mathrm{Dr}$, University of Padova, ITALY, francesca.corra@unipd.it \\ ${ }^{6} \mathrm{Dr}$, University of Padova, ITALY, gianfranco.santovito@unipd.it \\ ${ }^{*}$ Corresponding Author
}

\begin{abstract}
In the last decade, Science Education has played a crucial role in the training of young students, supporting them in understanding the world around us, making them active citizens, responsible and capable of innovation in a knowledge-based society (Recommendation of the European Parliament and of the Council, 18 December 2006).

The purpose of the presented experimental research, carried out in a fifth class of a Primary School in Treviso (Italy), was to test the validity of a teaching approach based on the scientific method, in particular on the observation-comparative method (characteristic of Evolutionary Biology), in the teaching of Life Sciences. The research focused on the planning and realization of a learning unit for the study of the human musculoskeletal system, made by a theoretical initial phase followed by a practical approach, which involved the comparison of anatomical structures of three vertebrates: trout, chicken and pig.

The experimental work was preceded by a survey on didactics, aimed to identify methods and teaching practices adopted by teachers of Natural and Experimental Sciences of the Primary School, especially for the Biology and in particular for the musculoskeletal system. For example, from this preliminary investigation it was found that the teachers of the Primary School do not use tools such as the stereoscope for viewing biological material, despite they claim to take an active approach for the teaching of Science and they have the appropriate scientific instruments.

The results have shown that despite the traditional teaching proposes the dissection of foot from chicken, an animal belonging to the class of birds, pig is the most suitable for the specific practical experimental teaching, because is a mammal and thus is more similar to human from the morphological point of view, as well as the phylogenetic relationships. Active teaching and direct observation of animal structures reinforced the concepts theoretically exposed. It was also confirmed the high teaching potential of the integration of macroscopic and microscopic observations.
\end{abstract}

The observational-comparative method is a key component for the study of the Biology; for this reason all the topics linked to the study of the human body can be addressed through the use of this active methodology. This kind of approach can motivate students, making them active participants in their own learning.

The most innovative aspect of the proposed experimental program is the comparison of the musculoskeletal system in three selected vertebrates. Although the Italian Guidelines for the Curriculum in the Primary School 
emphasize the importance of scientific comparison between animals and human, with the objective of learning at the end of the fifth class to continue the study of the functions of organisms and compare the reproduction of human, animals and plant, it is also true that the comparison should be also made between animals that do not include human, in particular for the systems important from the physiological point of view.

Keywords: laboratory didactics, life sciences, primary school, musculoskeletal system, scientific method.

\section{INTRODUCTION}

In the teaching of science, it's essential that one keeps in mind the complexity of the living and non-living world, as continuously changing systems. In order to make sure that pupils learn science in an organized and continuous way, the teacher has to start from their misconceptions, since each of us (and all the more so pupils) is a bearer of faulty thinking. Misconceptions are mental representations we have built for each phenomenon we learn about (Andena, 2007). Pupils' background knowledge can be noted during the discussions in the classroom, which make them aware of their ideas and allow them to reach the full accommodation of the new conception (Andena, 2007). In confirmation of this statement, scientific knowledge develops through thinking: it's the teacher's duty to create didactic situations in which the students' thought could develop and take shape in an appropriate way, so that they can interpret several situations of reality (Arcà, 1993).

The laboratory is the most appropriate context of learning for the study of science, and is not only considered as a place where tangible products are created with our hands by combining operating and thinking, but also and above all as an environment where one can attain certain new cognitive styles rather than others (Alfieri et al., 1995). Activities in the laboratory allow students to have a debate, sharing ideas and knowledge. In the science laboratory students learn how to look at certain objects and to make some phenomena happen, they share the already available explanations and together they build more adequate ones within an integrated and recursive process (Alfieri et al., 1995).

At the root of the study of Science there's the scientific method, which allows the passage from the perceptible phenomena in the environment or in everyday life to the underlying theories through processes of schematization, formalization, imposition - recognition of the connections between systems and variables (Arcà, 1993). The scientific method facilitates the recognition of similarities and differences, the choice of effective cognitive strategies and appropriate models, the experimental reproduction of aspects of reality (Santovito, 2015). The phases of the scientific method are the following: observation of a phenomenon, formulation of hypotheses, scientific experimentation to test the hypotheses, formulation of a theory which confirms the initial hypothesis.

Longo (1998) underlines the descriptive aspect as the most relevant component of Biology. Through observation, Biology describes the living beings simply because they exist, with all their peculiar characteristics, without trying to immediately obtain universal laws from them. For this reason, the observational and descriptive methods are mainly adopted in the study of the human body.

Comparison is an instrument which guides scientific analyses and allows the formulation of hypotheses about the functions of the animal and vegetable structures.

In particular, the comparison of different animals helps to understand similarities and differences better, emphasizing the functional and evolutionary aspects the vertebrates carry inside their body (Kardong, 1995). Comparative anatomy is the subject studying the morphology of the vertebrate animals and its structural meaning.

Scientific studies have demonstrated that the way an animal is "built" is related to the functional requirements of the parts of its body: the anatomic structure and its function are connected. For example, it has been observed on a comparative level that different fish have tails with different shapes according to the use of the tail. Similar results have been obtained for a wide range of vertebrate animals.

\section{MATERIALS AND METHODS}

\subsection{Preliminary Analysis}

In order to verify the use of active didactics in the teaching of Science in the Primary School, and in particular in the study of the musculoskeletal system, we have chosen to do a preliminary analysis through the 
administration of a specially planned survey, which involved twenty-seven teachers from the Istituto Comprensivo 3 - Felissent in Treviso.

The survey is composed of three sections: an introductive part with the purpose of collecting information about the personal and professional characteristics of the teachers (educational qualifications, years of teaching service, participation to school projects) and the teaching-methodological choices in the teaching of Science (learning contents, the primary textbook as a basic instrument for the educational planning, the experimental method in the teaching of Science); the second part is dedicated to the teachingmethodological choices in teaching the four seasons, with particular reference to the plants; the third section deals with the teaching-methodological choices in teaching the musculoskeletal system, with particular reference to comparative anatomy.

The first section of the survey contains mainly close questions, while the sections regarding the single experimental courses consist of open questions.

This survey has been useful to obtain an (although limited) outline of the ways which didactics of Science is conducted with in the Primary School.

With this analysis we have chosen to investigate on the existence of correlations between the personal or professional characteristics of the teacher and methods, teaching practices and instruments (magazines, manuals, etc) adopted in the teaching of Science.

With reference to the experimental course, we wanted to verify whether teachers use the primary textbook as main instrument to teach the musculoskeletal system or join it with laboratory activities, using the optical microscope or the stereoscope. Furthermore, we wanted to investigate on the practice of dissecting and observing animal anatomical structures.

\subsection{Experimental Phase}

In a preliminary stage we have chosen to administer the pupils a form, in order to investigate their background knowledge about bones and muscles in humans and animals.

As regards the proposals formulated in the analysed documents, Alfieri and co-workers (1995), proposed an activity about movement using the dialogic-conversational-argumentative method to investigate the background knowledge of the pupils. The questions put and listed in the text are the following: "How do you move?", "What makes you move?", "Which are the rigid and the movable parts of your moving body?". We decided to adapt these questions and create a form to know in detail the pupils' background knowledge about movement, asking children to draw some pictures, with the rigid parts of the body in blue, while the moving parts in red.

To observe the structure of the human body we chose to watch eight X-ray photographs in the class, mainly reproducing limbs. This activity, drawn by Arcà (2005) and personally reworked, included the observation and comparison of X-ray photographs brought in class by pupils and us. The chosen images reproduced shoulder, the thoraxes of a young man and of a little girl, metacarpus, carpus and phalanxes of a hand, tibia, ulna and radius. We chose to use the X-ray photographs reproducing limbs since these structures are mainly involved in locomotion.

The experimental phase took place in the science laboratory of the school and included the observation and dissection of three vertebrates: trout, chicken and pig. In particular, the comparison of the three animals' musculoskeletal systems allows the observation of the characteristics fish, birds and mammals have in common from the phylogenetic point of view; furthermore it allows pupils to verify that pig, as a mammal, has such morphological characteristics which make him the fittest for the study of the human musculoskeletal system.

In particular, We have chosen to observe the body of a previously gutted trout, not to distract the pupils' attention from the focus of the observation, the section corresponding to the thigh of a chicken and the anatomic region of tibia and fibula of a pig.

Furthermore, to analyse the bone marrow contained in the long and short bones of a mammal, we have used a section of a pig's femur, the one commonly called marrowbone, and rib.

\section{RESULTS}

\subsection{Results of the Preliminary Analysis}

From the analysis of the given answers it comes out that Science teachers took part to school projects, when offered. 
As regards the teaching-methodological choices about Science, the first question was about the consultation of specific teaching magazines on the subject, and it has come out that only three teachers kept up-to-date about the results of teaching research (they are in contact with the Research Centres); on the contrary, almost all the sample uses Magazines of general didactics containing also Science, that is they didn't keep up-to-date specifically on Science.

The answers to questions concerning methods, teaching practices and the use of instruments such as stereoscope and microscope for the experimental observation are shown in Fig. 1 and Fig. 2.

\section{Methods and teaching} practices

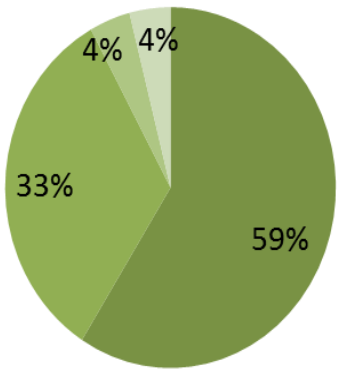

Active
Method or teaching practice preferred by pupils

Integrated

Transmissive

No response

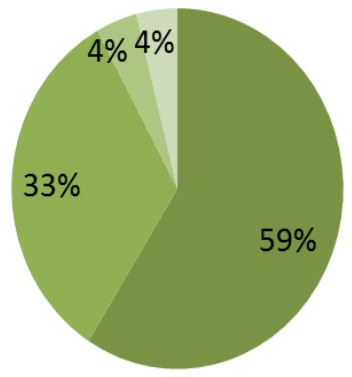

Fig.1. Percentage of answers to the questions "Which methods and teaching practices do you prefer in the teaching of Science?" - "Which method or teaching practice do you believe pupils like the most?"
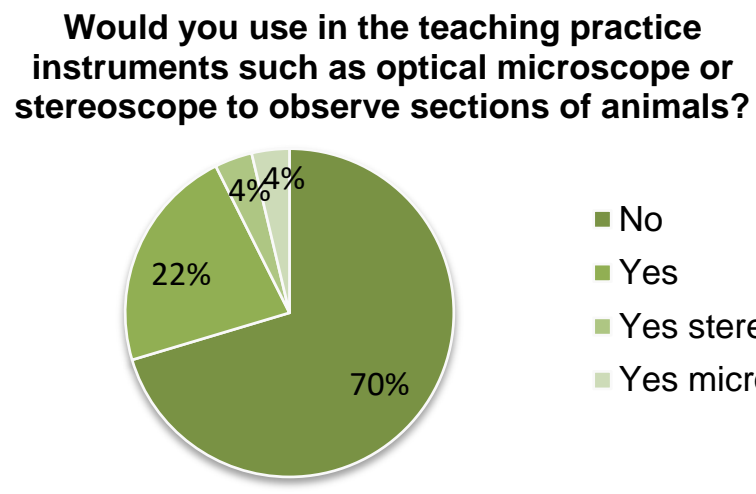

$$
\begin{aligned}
& =\text { No } \\
& =\text { Yes } \\
& =\text { Yes stereoscope } \\
& =\text { Yes microscope }
\end{aligned}
$$

Fig.2. Percentage of answers to the question "Would you use in the teaching practice instruments such as optical microscope or stereoscope to observe sections of animals?".

We deduce that teachers assert they mainly use an active method or an integration of active and transmissive methods (a total of $92 \%$ ), and that the former is particularly appreciated by pupils; but the result of the answers to question 28 is perplexing, where we infer that instruments such as the stereoscope and the optical microscope don't belong to the teaching practice. These instruments are at the root of the scientific method and therefore of active teaching. From a detailed analysis of the answers we notice that teachers don't use such aids because they don't have at their disposal an equipped Science laboratory and instruments "in good repair"; some simply assert they didn't have the chance.

The third and last section of the survey is dedicated to the teaching-methodological choices in the teaching of the musculoskeletal system, with reference to comparative anatomy, and is connected to the experimental activity discussed in this paper. The answers given to the first question "Which methods and teaching practices do you prefer in the teaching of the musculoskeletal system?" are classified into four categories, as reported in Fig.3. 


\title{
Quali metodologie e pratiche didattiche predilige nell'insegnamento dell'apparato locomotore?
}

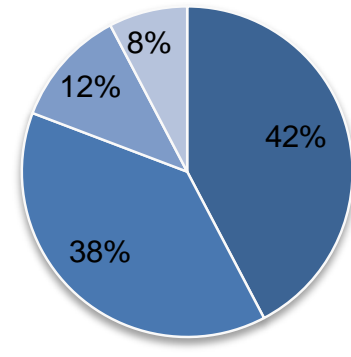

\author{
- Active \\ - Integrated \\ - Transmissive \\ No response
}

\section{Fig. 3. Percentage of answers to the questions "Which methods and teaching practices do you prefer in the} teaching of the musculoskeletal system?"

The data show that most of the teachers assert they use the active method (mentioned in $42 \%$ of the answers) and the integrated method (38\% of the answers). These data are interesting and odd, since, in the previous section, as regards the question "Would you use in the teaching practice instruments such as optical microscope or stereoscope to observe sections of animals? If yes, have you ever used them in a fifth class? Why?" shown in picture $4.4,74 \%$ of the teachers don't use stereoscope and optical microscope for the analysis and observation of sections of animals. We can therefore assert that the given answers are contradictory.

Going on decoding the survey, to the question "Have you ever thought of dealing with the human musculoskeletal system through the comparison with the animal anatomy?", ten teachers gave a positive answer, on the contrary the remaining seventeen chose the negative answer and in some cases they explained their reasons ("I don't know the subject enough", "The study of animals belongs to the science program for the fourth class", "The hours dedicated to science during the week in a fifth class is reduced and it would be very difficult to deal with this subject, too".)

In the end the question "Which animals do you think are fittest to carry out such experimental activity?" required a choice among the following options: trout, chicken, pig, all the above-mentioned animals.

From the analysis of the answers given by the teachers it's possible to assert that the initial hypothesis of the experimental course has been confirmed: chicken, although belonging to the class of birds and not of the mammals, is considered the fittest for a study on the human anatomy. The following are some significant answers to the question "Why (would you use trout, chicken, pig or all the above mentioned animals)?": i) Trout, because it costs less, it's an animal pupils are accustomed to and is small-sized; ii) Chicken, because it's easier to find, the most known; iii) Pig, because is more similar to humans.

\subsection{Results of the Experimental Phase in the Class}

\subsubsection{Investigation on Background Knowledge}

The initial form, created for the investigation of the background knowledge about bones, muscles and vertebrates ("What do we know about movement?"), allowed us to obtain useful results for the following phases of the experimental course.

The form was filled by sixteen pupils of a fifth class during the session introducing the learning unit; in the first question "You move when...", only three pupils recognised the voluntary component of the human musculoskeletal system, by choosing the first answer. Seven pupils chose the second option, asserting that, during the movement, bones and muscles move independently. The remaining six opted for the third answer, marking both the first and the second options as valid. From the obtained answers we deduce that only three pupils out of sixteen gave the correct answer: the movement of our body starts from our brain.

As regards the second question, which asked "What are the bones?", the given answers have been grouped into five categories, according to their occurrence. By observing the chart one can notice that $53 \%$ of the pupils recognised the supporting function of the bones. The use of the bones for the movement has been stated in $21 \%$ of the cases, while the remaining percentage is divided among the categories "They are rigid structures", "They form the skeleton", "They are made up of cells", in the percentage of $10 \%, 11 \%$ and $5 \%$ 
respectively.

The importance of muscles in the body movement has been highlighted in $70 \%$ of the answers to the question "What are the muscles?". 18\% of the answers show a children's misconception: muscles form only some parts of our body. The remaining percentage regards the structural characteristics of the muscles (muscles are elongated and elastic and are made up of cells).

Going on with the analysis of the form, as to the question "Do all the animals have bones?", only one pupil chose the positive answer, the remaining fifteen gave the negative one. Then they were asked "If the answer is no, which animals have bones?" The percentage of answers of the fifteen pupils has been grouped into six categories, shown in Fig. 4.

\section{Which animal have bones?}

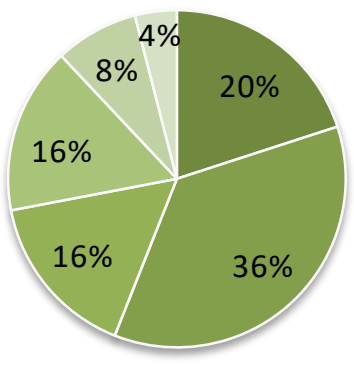

- Vertebrates

- Mammalians

- Birds

Fish

Amphibians

Living organisms

Fig. 4. Percentage of the answers to the question "Which animals have bones?"

Only a small portion, 20\%, answered "Vertebrates". The class of mammals is recognised as possessor of bones in $36 \%$ of the answers; the answers contain also other classes of vertebrates, such as birds (16\%), fish (16\%) and amphibians (8\%). A very small percentage, $4 \%$ of the pupils, recognises bones as a structure belonging to all of them.

To the answer "Do all the animals have muscles?", seven pupils gave the positive answer, while the remaining ten chose the "No" option. We can suppose that the low number of positive answers, but which is higher than the previous question's ("Do all the animals have bones?"), makes reference to a children's misconception: all the animals move, so all the animals have muscles.

The following question required, in case of negative answer, to mark which animals are provided with muscles.

The $25 \%$ of the answers given by the ten pupils regards vertebrates (Fig. 5 ). In $42 \%$ of the cases students mention mammals as animals provided with muscular system. Finally, the remaining classes of animals they make reference to are: birds, with a $9 \%$ percentage, fish (8\%) and amphibians (8\%). The remaining $8 \%$ of the answers regards the invertebrate animals.

\section{Which animals have muscles?}

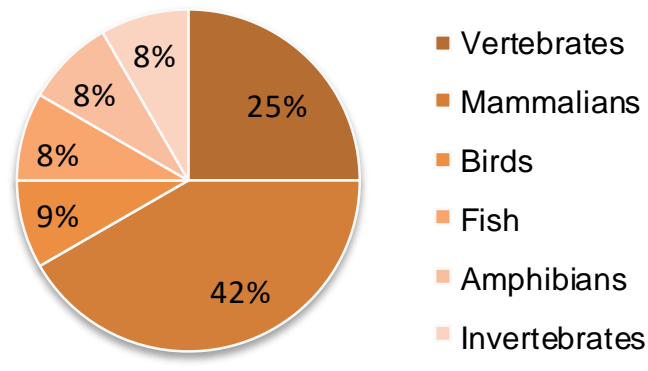

Fig. 5. Percentage of the answers to the question "Which animals have muscles?" 
To conclude the analysis of background knowledge, children drew some pictures; as demanded by the form described in materials and methods ("What do we know about movement?"), the rigid parts of the body are drawn in blue, while the moving parts in red.

\subsubsection{Laboratory Phase}

The experimental activity took place in the science laboratory of the school and included the dissection and observation of trout, chicken and pig. The observation and dissection of the meat took place on three different tables: a table dedicated to the trout, properly washed and gutted, a table for the chicken thigh and a third table for the pig.

The pupils, after wearing their white coats and latex gloves, placed themselves around the first table. After a brief introduction about the focus of the scientific observation (musculoskeletal system in vertebrates), we incised the body of the trout below the dorsal fins. The incision allowed me to lift epidermis (the external part of the skin) and dermis (layer situated in the internal part of the skin, richly vascularized), showing the muscular structures of the trout. Pupils commented and indicated a substantial difference between the muscles near the caudal fin and the dorsal muscles: the caudal fin has a propulsive role in the movement of fish, for this reason its muscles are stronger. Students experienced the differences by touch.

Then we incised in the middle of the muscles to let them observe the spine and the ribs of the fish. Through our guide, the pupils verified that joints are in the fins of the fish, subdivided into ventral (which create a sort of rudder and allow the fish to move in various directions), dorsal (which give stability to the animal avoiding overturns in case of sudden movements) and caudal (which have a propulsive effect).

The experimental activity went on by dissecting the chicken thigh, corresponding to the anatomic region of tibia and fibula. We incised the skin and the adipose tissue to lay the fascicles of muscles bare and observe their arrangement. In this way it was possible to see also bones and tendons. Then a discussion started to remind the anatomical characteristics of birds, already studied in the fourth class. The dissection stimulate the students' curiosity about the composition of bones. We then decided to satisfy the student curiosity by continue the dissection further and cut crosswise one of the bone to verified their hypothesis.

In the third and last phase of the analysis we observed the limb of the pig paying particular attention to the distinction between long and short bones. After a brief introduction, during which the characteristics of mammals have been listed, class of vertebrates also humans belong to, pupils observed the portion of the pig's lower limb, which includes the anatomic region of tibia and fibula. We have verified that, unlike the chicken bone, the pig's bone is extremely resistant and is composed by diaphysis and epiphysis like human bone.

\section{DISCUSSION}

In the World and European scene, many studies analysed what are the most significant approaches to improve the learning (Gaiotto et al., 2013; Tonon et al., 2013; Pavan and Santovito, 2014; Zandonella et al., 2014; Toninato and Santovito, 2015; Trevisan and Santovito, 2015; Gaiotto and Santovito, 2016; Rossi and Santovito, 2016; Capparotto et al., 2017; Favaron et al., 2017; Lago et al., 2017; Meneghetti et al., 2017; Barbacovi et al., 2018; Fassinato et al., 2018; Forlin et al., 2018; Grando et al., 2018a, 2018b; Tura et al., 2018; Chiesa et al., 2019; Gallina et al., 2019; Lui et al., 2019; Palmieri et al., 2019; Corbolino et al., 2020; Zanata and Santovito, 2020). Nevertheless, these practices were found not used in the Italian school.

As regards the comparison of the three vertebrates for the study of the musculoskeletal system, the preliminary survey on didactics reveals that to the question "Which animals do you think are fittest to carry out such experimental activity?" only $7 \%$ of the answers given by the teachers indicated "All the above mentioned animals", so trout, chicken and pig. For this reason, it's possible to recognise the originality of the course carried out in the fifth class, at least as for the school of reference. In the same way chicken was marked in $47 \%$ of the answers as the fittest animal for the comparison with humans, contrary to the pig which was mentioned only in $14 \%$ of the cases. From the analysis of the results obtained during the experimental course came out that pig is the fittest animal for the study of the human musculoskeletal system because, as a mammal, it has similar anatomical structures, and this proves our second experimental hypothesis.

As regards the course we carried out, we would like to add some specific comments about the various phases.

Although all (or almost all) the students knew which animals have a bone skeleton, only few of them (only $21 \%$ ) stated bones are important for movement. This datum is indicative of the fact that this important knowledge doesn't originate from school activities, but from background knowledge gained in other situations. That's not positive, because animals are normally studied during the previous years (and in 
particular in the fourth class) and a characteristic which is surely highlighted in these organisms is movement, which requires not only the presence of muscles, but also of a skeleton the muscles can connect to. We can even suppose that the teacher didn't explain the concept that all the animals (not only vertebrates) have a skeleton. So, it would have been interesting to ask the question "Which animals have a skeleton?". Anyway, there's still the possibility that pupils didn't assimilate these concepts well, and the cause could lie anyway in the teaching methods that were used.

The experimental phase of dissection, observation and data collection is the strength of the course, and is coherent with what written in the draft of the new Curricular Indications for childhood education and primary schooling (may 2012): "The observation of facts and the spirit of research should be characteristics also of an effective teaching of Science, which should be carried out through a direct involvement of the pupils, encouraging them, without a rigid temporal order and without forcing any phase, to ask questions about phenomena and things, to plan experiments/explorations following working hypotheses and to build interpretive models". About the exploration and the dissection of organisms, Alfieri and co-workers (Alfieri et al., 1995) suggested that the research of similarity and differences is a work that can be carried out since the first classes. They propose to observe bodies of animals which haven't been gutted, such as the interior of a trout, of a chicken or the heart of an ox with its arterial vessels, a chicken's digestive tract. Despite the above-mentioned teaching suggestions have been formulated almost two decades ago, from the preliminary survey conducted in the school Istituto Comprensivo 3 - Felissent Treviso on an experimental sample of twenty-seven teachers, most of the teachers specified the need of an expert to carry out the experimental activities. We can so deduce that, taking into consideration the schools' present difficulties in finding experts and valid support for the teaching, experimental dissection and observation seldom take place. Seven negative answers highlighted the lack of means and instruments, as well as children's excessive emotiveness, which in my opinion is not a characteristic of puberty, but a consequence of the fact that children are not familiar with such experiences. The organization of the Science lab has a crucial role in the active experimentation of phenomena. Andena (2007) states that Frontal lecturing is reduced to a minimum and will be used only in the initial phases or to summarize the results of common discussions. An ideal situation which can be re-created is the regrouping of desks into work islands. Our experimental activity proved that, although lacking in a science laboratory, it's possible to prepare in the classroom a proper setting for the active teaching. The above-mentioned observations can be carried out simply, one can recycle the waste of a butchers. The aspect we consider not to be set aside is the teacher's training, who must show confidence and resolution when doing such activities (Arcà, 2005); in this way pupils won't be overcome by the emotional component and will observe with interest and learn real information, actively experimented.

Strength of the course is also the observation of the anatomical structures to the naked eyes, with magnifying glass or stereoscope. Observation is a learning objective to be reached at the end of the fifth class of Primary School (2007 Curricular Indications), although the preliminary survey shows that only $18 \%$ of the teachers uses stereoscope to observe sections of animals. In particular, the macroscopic observation has been useful, in addition to highlight similarities and differences among the anatomical structures of the different species, because it was integrated with the manipulation, which allowed the pupils to perceive in the best possible way the texture of the structural components of the of the musculoskeletal system (bones, cartilages, tendons). The macroscopic observation has been a useful instrument to improve and complete the previous activity, the most "hidden" components, such as bone marrow and tendons, or the smallest ones, such as the trout's bones and joints. Therefore, the results confirm the high teaching potential of the integration of macroscopic and microscopic observation.

In order to expand the teaching dimension, it would have been useful to use, in addition to the trout, also the gutted bodies of a chicken and of a rabbit, replacing the pig. This would have allowed the pupils to see where the observed anatomical structures are placed within the body, and to get more information and awareness. Such procedure could be used also to observe the interior of a chicken (not gutted), to study one by one the organs it's composed of. In fact, the pupils' final conclusions revealed their wish of a deeper study of the internal organs of the three animals ("I wished the trout had its organs inside"), but this was beyond the objectives regarding the musculoskeletal system. On the contrary it would have been interesting to deal with the topic explaining how the different locomotor structures (fins, paws, wings) were fit for the environment where the animal lives and for its behaviour (habitus).

An activity we could maybe add to this course is the view under a microscope, which, according to the preliminary survey, turns out to be seldom used (only in $4 \%$ of the cases) for the observation of animal tissues. In the specific instance, the use of a microscope would allow, for example, to observe the cells which make up the muscular and bony tissues. 
The most innovative aspect of this experimental approach is the comparison of the musculoskeletal system of the three chosen vertebrates: trout, chicken and pig. Actually, if it's true that the 2007 Curricular Indications emphasize the importance of the scientific comparison between humans and animals, putting as a learning objective at the end of the fifth class "to go on with the study of the functioning of the organisms and to compare human, animal and vegetable reproductions", it's as true that this should concern also other systems which are important from the physiological point of view. Furthermore, the comparative approach is at the root of the study of evolution, a topic deeply studied in the Secondary School, but which should be dealt with already in the Primary School, although with lower levels of complexity.

\section{REFERENCE LIST}

Alfieri, L., Arcà, M. \& Guidoni, P. (1995). II senso di fare scienze: Un esempio di mediazione tra cultura e scuola. Bollati Boringhieri Editore, Torino.

Andena, T. (2007). Insegnare con i concetti le scienze. Franco Angeli Editore, Milano.

Arcà, M. (1993). La cultura scientifica a scuola. Franco Angeli Editore, Milano.

Arcà, M. (2005). Il corpo umano. Carocci Faber, Roma.

Barbacovi, V., Santovito, G. \& Irato, P. (2018) Little scientists for large discoveries: an experimental approach to survey the world with classes ii of the primary school - The observation and study of plant life. In: EDULEARN18 Proceedings, IATED, Valencia. https://doi.org/10.21125/edulearn.2018.1579

Capparotto, A., Bramuzzo, S., Callegaro, E., Poloni, E., Corrà, F. \& Santovito G. (2017) The didactics of biology in primary school: an innovative approach to skeletal system teaching in fifth class based on comparative vertebrate anatomy. In: INTED2017 Proceedings, IATED, Valencia. http://doi.org/10.21125/inted.2017.0935

Chiesa, E., Irato, P. \& Santovito, G. (2019) The circulatory system of vertebrates and invertebrates: an empirical research to introduce in the fourth class the treatment of animal morphology in a comparative key. In: INTED2019 Proceedings, IATED, Valencia. https://doi.org/10.21125/inted.2019.0391

Corbolino, N., Bisaccia, P., Corrà, F., Bonato, M., Irato, P. \& Santovito G. (2020) The vegetable garden. An instrument for sustainable development education and care pedagogy. In: INTED2020 Proceedings, IATED, Valencia. https://doi.org/10.21125/inted.2020.1282.

Fassinato, C., Nicorelli, E., Corrà, F., Irato, P., Guidolin, L. \& Santovito G. (2018) An innovative approach to deal with biodiversity at school with its investigation in different environments. In: EDULEARN18 Proceedings, IATED, Valencia. https://doi.org/10.21125/edulearn.2018.0717

Favaron, A., Ancona, E., Bramuzzo, S., Callegaro, E., Guidolin, L., Irato, P. \& Santovito, G. (2017) An innovative teaching approach to circulatory and skeletal systems based on comparative vertebrate anatomy and physiology. In: EDULEARN17 Proceedings, IATED, Valencia. http://doi.org/10.21125/edulearn.2017.1015

Forlin, E., Santovito, G., Guidolin, L. \& Irato, P. (2018) Citrus fruits. Course to educate to scientific curiosity. In: EDULEARN18 Proceedings, IATED, Valencia. https://doi.org/10.21125/edulearn.2018.1573

Gaiotto, A., Tonon, S. \& Santovito, G. (2013) The scientific method in the teaching of life sciences in primary school, The plants and their seasonal changes". In EDULEARN13 Proceedings, pp. 4226-4235.

Gaiotto A., Santovito G. (2016) An innovative didactic approach to the study of invertebrate animals in primary school. In: EDULEARN16 Proceedings, IATED, Valencia. http://doi.org/10.21125/edulearn.2016.1284

Gallina, S., Irato, P. \& Santovito, G. (2019) Inquiry into animal tracks: an experimental application of IBSE inquiry based science education- approach in the ecological field in primary school. In: INTED2019 Proceedings, IATED, Valencia. https://doi.org/10.21125/inted.2019.0089

Grando, G., Bramuzzo, S., Irato, P., Guidolin, L., Ferrari, L. \& Santovito, G. (2018) Introduction to the world of insects: a didactic research in kindergarten. In: INTED2018 Proceedings, IATED, Valencia.

https://doi.org/10.21125/inted.2018.1066 
Grando, G, Bramuzzo, S., Callegaro, E., Guidolin, L., Irato, P. \& Santovito, G. (2018) Who is afraid of insects? A didactic research in the biological field in kindergarten. In: EDULEARN18 Proceedings, IATED, Valencia. https://doi.org/10.21125/edulearn.2018.0724

Kardong, K.V. (1995). Vertebrates: Comparative anatomy function evolution. Wm. C. Brown Publishers, Dubuque, Melbourne, Oxford.

Lago, A., Masiero, S., Bramuzzo, S., Callegaro, E., Poloni, E., Corrà, F. \& Santovito G. (2017) Exploring microbiology and biotechnologies: a laboratory approach to the study of yeasts and bacteria in primary school. In: INTED2017 Proceedings, IATED, Valencia. http://doi.org/10.21125/inted.2017.0992

Longo, C. (1998). Didattica della biologia. La Nuova Italia Editrice, Firenze.

Lui, F., Irato, P. \& Santovito, G. (2019) Discovering living organisms: a didactic research to introduce biology in kindergarten. In: EDULEARN19 Proceedings, IATED, Valencia. https://doi.org/10.21125/edulearn.2019.1040

Meneghetti, G, Bramuzzo, S., Callegaro, E., Guidolin, L., Irato, P. \& Santovito G. (2017) The kingdom of fungi in primary school: an educational research in biology field. In: EDULEARN17 Proceedings, IATED, Valencia. https://doi.org/10.21125/edulearn.2017.1023

Palmieri, G., Irato, P., Nicolosi, P. \& Santovito, G. (2019) A day at the museum. Laboratory teaching in the Museum of Zoology at the University of Padua for primary school. In: EDULEARN19 Proceedings, IATED, Valencia. https://doi.org/10.21125/edulearn.2019.1037

Pavan, C. \& Santovito, G. (2014) The laboratory didactics in the teaching -learning processes of life sciences. an educational project on microorganisms in the alimentation in primary school. In: EDULEARN14 Proceedings, IATED, Valencia, pp 7546-7555.

Rossi, E. \& Santovito, G. (2016) Introduction to Mendelian genetics in primary school. In EDULEARN16 Proceedings, IATED, Valencia. http://doi.org/10.21125/edulearn.2016.1274

Santovito, G. (2015) Insegnare la biologia ai bambini. Dalla scuola dell'infanzia al primo ciclo d'istruzione. Carocci, Roma.

Toninato, V. \& Santovito, G. (2015) The laboratory didactics in the teaching-learning processes of life sciences. an educational project on the structure of the flower and the inflorescences phenomenon in primary school. In: EDULEARN15 Proceedings, IATED, Valencia, pp 2245-2254.

Tonon, S., Gaiotto, A. \& Santovito, G. (2013) The active teaching of life sciences in primary school: a comparative approach to the musculoskeletal system. In: EDULEARN13 Proceedings, IATED, Valencia, pp. 4289-4298.

Trevisan, T. \& Santovito, G. (2015) Teaching evolution: a laboratory approach. In: EDULEARN15 Proceedings, IATED, Valencia, pp 2234-2244.

Tura, N., Guidolin, L., Irato, P. \& Santovito, G. (2018) From cell to inheritance of characters: an introduction to classical genetics in primary school. In: INTED2018 Proceedings, IATED, Valencia. https://doi.org/10.21125/inted.2018.1076

Zanata, M. \& Santovito, G. (2020) The "Da Vinci" Biodiversity Park (Treviso, Italy). A didactic garden as innovative support to the teaching of science in secondary school. In: INTED2020 Proceedings, IATED, Valencia. https://doi.org/10.21125/inted.2020.1474.

Zandonella Necca, I., Tamino, G. \& Santovito, G. (2014) Sustainable food: an educational proposal, for key stage 3 in secondary schools, based on the assessment for learning method. In: EDULEARN14 Proceedings, IATED, Valencia, pp 7348-7356. 